\title{
Situational interest, computer self-efficacy and self-regulation: Their impact on student engagement in distance education
}

\section{Jerry Chih-Yuan Sun and Robert Rueda}

Jerry Chih-Yuan Sun is an Assistant Professor in the Institute of Education and Center for Teacher Education at National Chiao Tung University. He was previously a Postdoctoral Research Associate in the Center for Scholarly Technology at University of Southern California. Address for correspondence: Jerry Chih-Yuan Sun, Center for Scholarly Technology, University of Southern California, 650 W. 35th Street, Los Angeles, CA 90089-2571, USA. Telephone: (323) 963-3389; fax: (213) 740-7713; email: csun@usc.edu. Robert Rueda is a Professor in the Rossier School of Education at University of Southern California. Address for correspondence: Robert Rueda, Rossier School of Education, University of Southern California, 3470 Trousdale Parkway, Los Angeles, CA 90089-4036, USA. Telephone: (213) 740-2371; email: rueda@usc.edu

\begin{abstract}
This study investigates possible relationships among motivational and learning variables (interest, self-efficacy and self-regulation) and three types of student engagement (behavioural engagement, emotional engagement and cognitive engagement) in a distance education setting. Participants were 203 students enrolled in online classes in the fall semester of 2008 in the Schools of Gerontology and Engineering at a large research university in the south-western USA, who completed an online survey assessing their levels of situational interest, computer self-efficacy, self-regulation and engagement in distance education. Situational interest and self-regulation were found to be significantly correlated with three types of engagement (behavioural, emotional and cognitive), while computer self-efficacy did not appear to be associated with any of those engagement variables. Results suggested that online activities and tools such as multimedia and discussion boards may increase emotional engagement in online learning, although they do not necessarily increase behavioural or cognitive engagement, that educators should identify students who are taking online courses for the first time and provide necessary technical help to increase their emotional engagement, and that it is important for educators to offer students strategies for increasing their self-regulation in distance education environments.
\end{abstract}

\section{Introduction}

Distance education technology allows students to take advantage of the convenience and flexibility of taking classes at the times and locations they prefer. Although distance education is convenient and can potentially employ rich multimedia materials, there are unresolved issues related to students' engagement in the learning process. In contrast to the environment in traditional educational settings, distance education instructors and peers are not physically present in a classroom, so students may lack opportunities to interact, collaborate and receive feedback and social support, thus leading to less engagement in learning activities (Tuckman, 2007). Moreover, distance education provides students much more freedom in how and when they interact, and therefore, their ability to regulate their own learning seems to be critical. Given the potential limitations associated with limited supervision, monitoring of student progress and opportunities to provide feedback to students, it would be useful for distance 


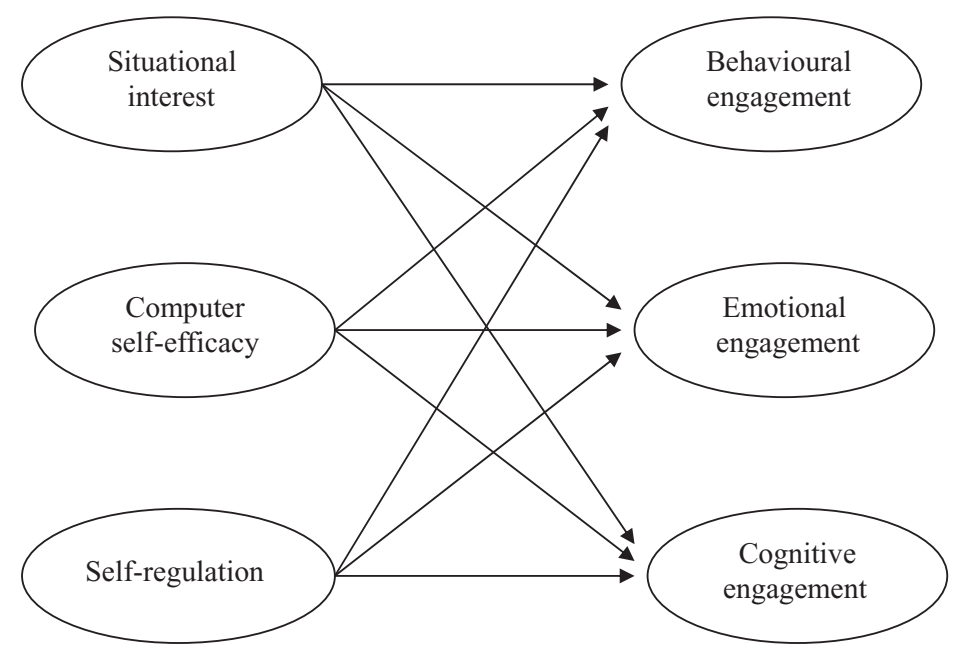

Figure 1: Model of research questions

education instructors and course designers to have a better understanding of what factors influence student engagement.

There have been many studies indicating that motivational and learning factors such as interest, self-efficacy and self-regulation are positively linked to student engagement levels (Bates \& Khasawneh, 2007; Dembo, Junge \& Lynch, 2006; Kanuka, 2005). However, little research has empirically explored how these factors may influence specific types of engagement. Therefore, the purpose of this study is to explore the motivational and learning variables (interest, self-efficacy and self-regulation) and their effects on student engagement in a distance learning setting.

In the current study, as outcome measures, we used Fredricks, Blumenfeld, Friedel and Paris (2005) and Fredricks, Blumenfeld and Paris' (2004) conceptualisation of engagement as being composed of behavioural, emotional and cognitive components. In addition, the following constructs were included in this study as independent variables: personal and situational interest (Hidi, 1990, 2006), computer self-efficacy (Bates \& Khasawneh, 2007) and self-regulation (Dembo et al, 2006; Zimmerman \& Risemberg, 1997). A brief conceptual model of the research is shown in Figure 1. The overarching research question of this study was: how do interest, self-efficacy and self-regulation influence engagement of distance education learners?

\section{Literature review}

There is a significant body of research findings that support the connection between motivational variables, learning strategies, self-regulatory behaviour and academic achievement (Bandura, 1997; Zimmerman \& Schunk, 2001). Therefore, there is increasing attention to motivational and learning variables as factors influencing student outcomes in online settings that have been less studied than traditional classroom settings. The following section provides an overview of the key variables examined in the study.

\section{Situational interest}

Situational interest refers to the interest activated by the immediate environment (Hidi, 2006; Schraw \& Lehman, 2001). In this study, the environment referred to distance education. There have been very few studies of interest and engagement in distance education environments. Most studies have been conducted in the context of traditional classrooms. For example, researchers have found that novelty enhances students' situational interest as well as engagement in the 
classroom setting (Chen, Darst \& Pangrazi, 1999; Flowerday, Schraw \& Stevens, 2004). The classroom context literature is valuable because results of distance education can be compared with results from traditional classroom education.

\section{Computer self-efficacy}

Self-efficacy is defined as '[P] eople's judgments of their capabilities to organize and execute courses of action required to attain designated types of performances' (Bandura, 1986, p. 391). Although there are many motivational constructs, self-efficacy is central to promoting students' engagement and learning. These context-specific and domain-specific beliefs affect behaviour by influencing the choices that people make and the courses of action they follow (Linnenbrink \& Pintrich, 2004).

Compeau and Higgins (1995) defined computer self-efficacy as one's perceived ability to accomplish a task with the use of computer. Many researchers (Compeau \& Higgins, 1995; Kinzie, Delcourt \& Powers, 1994; Stone \& Henry, 2003) have found that training and experience play important roles in computer self-efficacy, suggesting that students' computer self-efficacy is higher if they receive training or have experience using computer technology before taking distance education courses. In a recent research, Bates and Khasawneh (2007) found that students with higher computer self-efficacy tended to spend more time using online learning technology and were therefore more engaged in the learning processes.

Research on computer self-efficacy has focused on how antecedent variables affects students' self-efficacy and how self-efficacy influences outcome expectancy (Bates \& Khasawneh, 2007; DeTure, 2004; Stone \& Henry, 2003). Antecedent variables include previous success, acquired skills, instructor support and encouragement, while outcome expectancy refers to beliefs about the outcomes people desire after accomplishing specific tasks (Bandura, 1986).

\section{Self-regulation}

Research has suggested that self-regulated learning incorporates cognitive, motivational and metacognitive dimensions and suggests the importance of self-regulatory skills in academic achievement (Zimmerman \& Schunk, 2001). In the context of distance learning, research on self-regulation and distance education focuses on how students self-regulate their learning activities to become successful distance education learners (Wolters, Pintrich \& Karabenick, 2005). Previous research has indicated that since distance education learners lack direct encouragement from instructors, they may be less self-regulated in engaging in class activities (Dembo et al, 2006; Kanuka, 2005; Wang \& Lin, 2007; Whipp \& Chiarelli, 2004). The review also showed that social cognitive processes play important roles in self-regulation (Pintrich, Schunk \& Meece, 2008). Online activities that focus on interaction, such as discussion boards, debates and brainstorming, can potentially facilitate online learners' social cognitive effects such as improved engagement and increased self-regulation (Kanuka, 2005; Seaman \& Fellenz, 1993).

\section{Engagement}

In academic settings, engagement refers to the quality of effort students make to perform well and achieve desired outcomes (Hu \& Kuh, 2002; Richardson, Long \& Foster, 2004; Richardson \& Newby, 2006). Previous research has indicated that several factors, such as the use of course tutors (Richardson \& Long, 2003), the quality of technology (Webster \& Hackley, 1997) and motivational factors (Bates \& Khasawneh, 2007; Dembo et al, 2006; Kanuka, 2005) are positively linked to student engagement levels in distance education environments. The concept of engagement has attracted increasing attention in the research of motivation and student achievement (Fredricks et al, 2005, 2004). This study sought to further explore how motivational and learning factors may influence specific types of engagement. The three types of engagement (behavioural, emotional and cognitive engagement) identified by Fredricks et al (2004, 2005) were used to frame the investigation of engagement issues. 
In summary, previous studies suggest that motivational and learning factors are positively linked to student engagement levels (Bates \& Khasawneh, 2007; Dembo et al, 2006; Kanuka, 2005). However, work to date has not examined distinct components of engagement. Furthermore, only limited research has been conducted to empirically explore the motivational and learning variables (interest, self-efficacy and self-regulation) and their effects on student engagement in a distance learning setting. Therefore, this study explores how motivational and learning factors were related to student engagement in a distance education setting. It was hypothesised that situational interest, computer self-efficacy and self-regulation positively affect three types of engagement (behavioural, emotional and cognitive engagement) of students participating in distance education classes.

\section{Methodology}

Research context

Data were gathered from students enrolled in online classes in the fall semester of 2008 in the Schools of Gerontology and Engineering at a large research university in south-western USA using an online survey sent to them via email. The university's provost announced an initiative to promote technology-enhanced learning and distance learning in 2006 to promote and enhance teaching and learning experiences through the use of technology and distance education. Both the School of Engineering and the School of Gerontology were among the facilitators of this initiative. The participating schools incorporated dedicated sections to undertake the development of distance education courses delivered through BlackBoard, a popular e-learning system.

\section{Participants}

Of the 203 students who participated in the survey, the female students $(n=67)$ represented $33.2 \%$ of the participants in this study, while the male students $(n=135)$ represented $66.8 \%$ of the participants. Their mean age was 29.67 [standard deviation $(\mathrm{SD})=7.28$ ], which may be slightly underestimated because $10.8 \%$ of the participants indicated they were older than 45 and their ages were treated as 45 in the mean calculation. Most of the participants were graduate students (95.6\%) who classified themselves as domestic students (96.6\%). The majority (83.3\%) took the courses in a completely online environment, meaning they did not attend any lecture classes. The rest of the students (16.7\%) took the classes in a mixed environment; in other words, they still went to campus for lectures but have the option of viewing the lectures online. Although the mixed environment classes required in-class attendance, they included a significant online component. The majority of the students $(71.8 \%)$ had prior experience taking distance education classes, and $68.6 \%$ had taken such courses two or more times previously. According to the students' self-reports, they logged on to the online course management system 3 hours per week on average. The $98.5 \%$ students who took the courses with a webcast feature (video-recorded lectures) spent an average of 2.46 hours per week watching the video-recorded lectures.

\section{Instrumentation}

The instruments used in this study were adapted from existing validated scales: the Motivated Strategies for Learning Questionnaire (MSLQ) (Pintrich \& De Groot, 1990), the Situational Interest Scale (Chen et al, 1999), the Web Users Self-Efficacy Scale (WUSE) (Eachus \& Cassidy, 2006) and the Engagement Scale (Fredricks et al, 2004, 2005). All of these scales used 5-point Likert rating ( $5=$ strongly agree, $4=$ agree, $3=$ neither agree nor disagree, $2=$ disagree and $1=$ strongly disagree).

\section{Self-regulation measure}

The MSLQ was developed by the National Center for Research on Improving Postsecondary Teaching and Learning at the University of Michigan in 1986 (Pintrich, Smith, Garcia \& 
McKeachie, 1991). The subscale self-regulation in this instrument was used to measure distance education student levels of self-regulation. The internal consistency coefficient (Cronbach's $\alpha$ ) was 0.677 for the self-regulation scale.

Situational interest

The Situational Interest Scale is a 24-item Likert-scaled instrument developed by Chen et al (1999). The total interest subscale in its Interest instrument was used to measure the levels of situational interest exhibited by the distance education students in the present study. The internal consistency coefficient (Cronbach's $\alpha$ ) was 0.825 for the self-regulation scale.

Computer self-efficacy

The WUSE is a 5-point Likert-scaled instrument designed to measure an individual's confidence in using the Internet (Eachus \& Cassidy, 2006). WUSE addresses four domains of Internet self-efficacy: (1) information retrieval, (2) information provision, (3) communications and (4) technology. Questionnaire items are divided into four subscales based on these four domains. The technology subscale (computer self-efficacy scale) was used to measure distance education student levels of self-efficacy in relation to technology. The internal consistency coefficient (Cronbach's $\alpha$ ) was 0.831 for the self-regulation scale.

\section{Engagement}

The Engagement Scale was adapted from a 5-point Likert-scaled instrument developed by Fredricks et al (2005; 2004) measuring three types of engagement: behavioural engagement, emotional engagement and cognitive engagement. Because the Engagement Scale was designed to measure children's levels of school engagement, some of the items had to be modified to measure engagement levels of graduate and undergraduate students in a distance education setting. The internal consistency coefficients (Cronbach's $\alpha$ ) were 0.880 for the emotional engagement scale, 0.746 for the cognitive engagement scale and 0.462 for the behavioural engagement scale. Since the internal consistency coefficient (Cronbach's $\alpha$ ) of the behavioural engagement scale resulted in an unacceptable value $(\alpha=0.462)$, exploratory factor analysis was used to analyse the 19 items on the engagement scale in order to determine which items loaded on which types of engagement. Results showed that three factors (emotional engagement, cognitive engagement and behavioural engagement) most distinctly described the variance in the data. Table 1 presents the factors, factor loadings, communalities and reliability statistics. The revised behavioural engagement scale included items BE-1, BE- 5 and CE-1, the revised emotional engagement scale was composed of items EE-1, EE-2, EE-3, EE-4, EE-5, EE-6 and CE-8 and the revised cognitive engagement scale included items CE-2, CE-3, CE-4, CE-5 and CE-6.

\section{Procedure}

In order to ensure that the confidentiality and human subjects requirement was met, the study passed the institutional review board process before data collection was initiated. The survey questionnaire was sent to 139 students in the School of Gerontology and 1261 students in the School of Engineering by emails, resulting in 203 valid responses.

\section{Results}

A summary of demographic variables including gender, school enrolled in, degree objective, international or domestic student (IoD), times taking distance education courses (TT) is presented in Table 2. In addition, a summary of the means, SDs and Pearson correlation coefficients of the motivational and learning factors (interest, self-efficacy and self-regulation), three types of engagement variables (behavioural engagement, emotional engagement and cognitive engagement), age and first time taking distance education courses (FT) are listed in Table 3. 


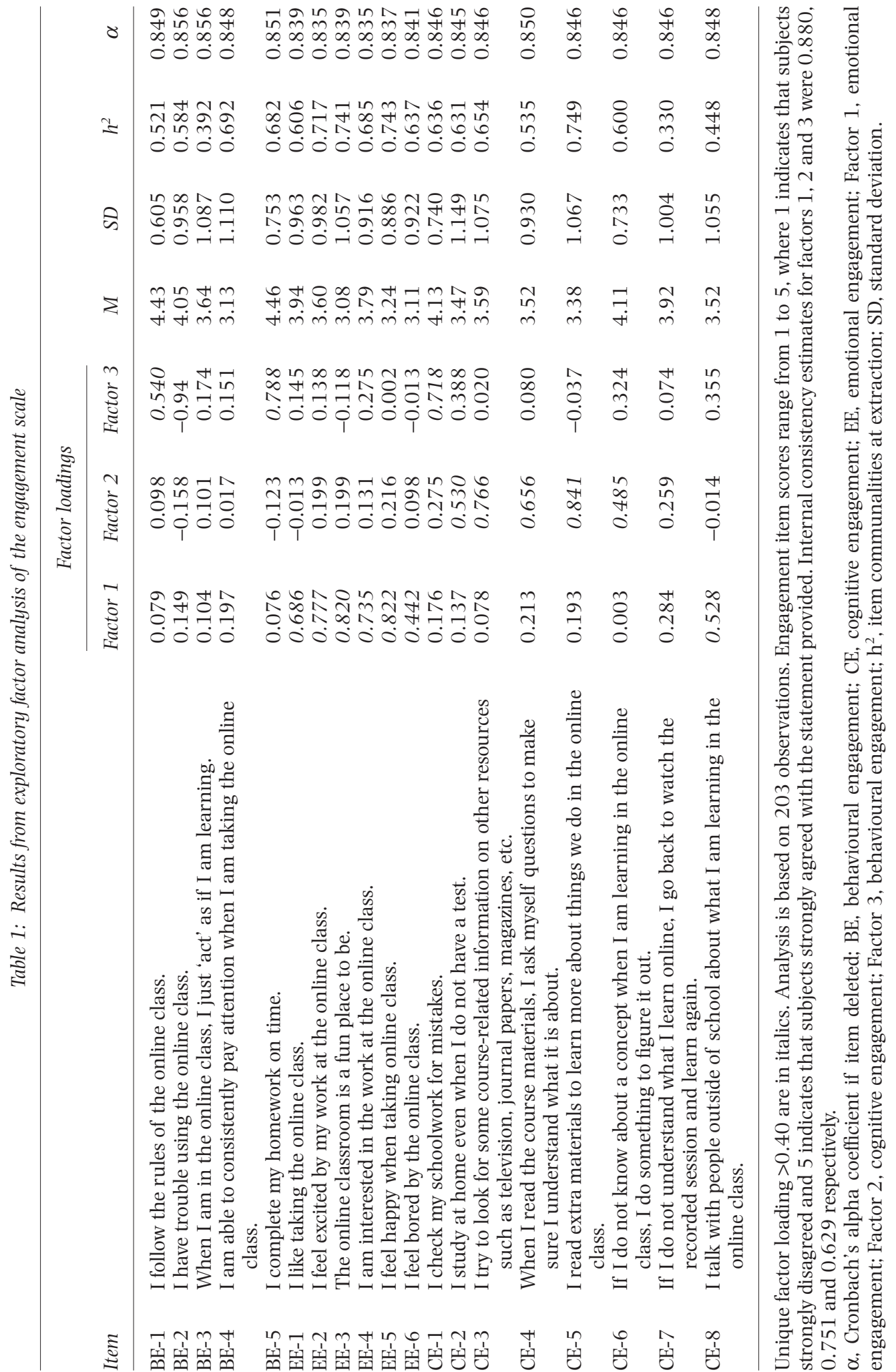


Table 2: Frequency and percentage of the participants by gender, school enrolled in, degree objective, IoD, and TT

\begin{tabular}{lr}
\hline & $n(\%)$ \\
\hline Gender & \\
$\quad$ Female & $67(33.2)$ \\
$\quad$ Male & $135(66.8)$ \\
School enrolled in & \\
$\quad$ Gerontology & $31(15.3)$ \\
Engineering & $172(84.7)$ \\
Degree objective & $4(2.02)$ \\
$\quad$ Certificate & $5(2.5)$ \\
Bachelor & $188(92.6)$ \\
Master's & $6(3.0)$ \\
PhD & $7(3.4)$ \\
IoD & $196(96.6)$ \\
International & $57(28.2)$ \\
Domestic & $145(71.8)$ \\
TT $\quad$ First time & \\
Two or more times & \\
\hline
\end{tabular}

IoD, International or domestic student; TT, time(s) taking distance education course(s).

Two of the motivational and learning factors, interest and self-regulation, were significantly correlated $(r=0.454, p<0.01)$, indicating that those participants with higher levels of interest also had higher levels of self-regulation. The correlation coefficient of 0.454 may raise concern about a multicollinearity problem between interest and self-regulation (Studenmund, 2006, p. 259). Thus, a variance inflation factor (VIF) was computed. Because the values of VIF (1.260 for interest and 1.268 for self-regulation) were lower than the conventional threshold (10), it was concluded that no multicollinearity problems existed.

In the analysis of intercorrelations between engagement variables (behavioural engagement, emotional engagement and cognitive engagement) and both independent variables (interest, self-efficacy and self-regulation) and control variables (participants' demographic information) in the research model, it was found that interest and self-regulation were significantly correlated with all types of engagement. Contrary to our hypothesis, there was no significant correlation between the participants' levels of computer self-efficacy with any of the engagement variables. Demographic variables that significantly correlated with emotional engagement or cognitive engagement were school enrolled in, FT, age and degree objective.

Hierarchical regression analyses showed how the motivational variables of interest and selfefficacy and the learning variable of self-regulation predicted each engagement variable (behavioural engagement, emotional engagement and cognitive engagement). Interest was only a significant predictor of emotional engagement. However, at the bivariate correlational level, interest had a relationship with all types of engagement. Self-regulation was a significant predictor of all types of engagement. Contrary to our expectations and previous research that students with higher computer self-efficacy are more engaged in the learning process (Bates \& Khasawneh, 2007), the participants' computer self-efficacy was not a significant predictor of engagement variables. Scatter plots between self-efficacy and all dependent variables (behavioural engagement, emotional engagement and cognitive engagement) were used to examine whether nonlinearity evoked in the form of a curved band or a big wave-shaped curve, for example, but non-linearity was not found. The results of hierarchical regressions are presented in Tables 4-6. 


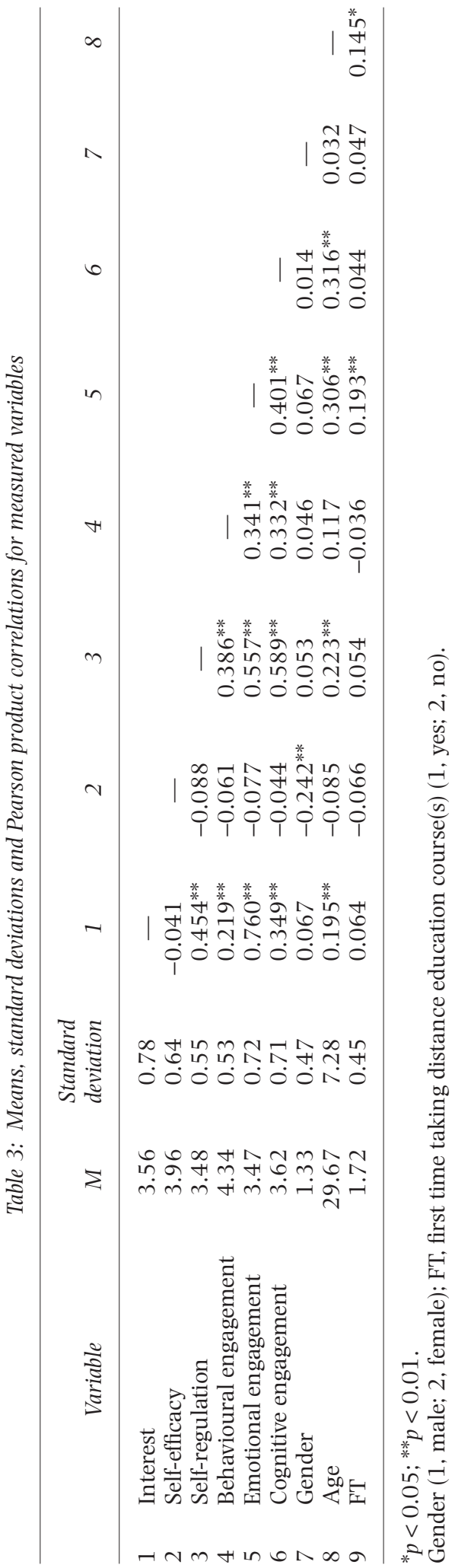


Table 4: Hierarchical regression analysis predicting behavioural engagement from motivational variables (interest and self-efficacy) and learning variable (self-regulation)

\begin{tabular}{lcrcr}
\hline Step and variable & $R^{2}$ & $B$ & SE B & \multicolumn{1}{c}{$\beta$} \\
\hline Step 1 & $0.051^{* *}$ & & & \\
$\quad$ (Constant) & & 3.984 & 0.289 & \\
Interest & & 0.148 & 0.047 & $0.217^{*}$ \\
Self-efficacy & & -0.043 & 0.057 & -0.052 \\
Step 2 & $0.152^{* * *}$ & & & \\
$\quad$ Constant) & & 3.089 & 0.330 & \\
Interest & & 0.038 & 0.050 & 0.055 \\
Self-efficacy & & -0.022 & 0.054 & -0.027 \\
Self-regulation & & 0.347 & 0.071 & $0.358^{* * *}$ \\
\hline
\end{tabular}

${ }^{*} p<0.05 ;{ }^{* *} p<0.01 ;{ }^{* * *} p<0.001$.

$\beta$, standardised coefficient; B, unstandardised coefficient; SE B, standard error.

Table 5: Hierarchical regression analysis predicting emotional engagement from motivational variables (interest and self-efficacy) and learning variable (self-regulation)

\begin{tabular}{lcrcc}
\hline Step and variable & $R^{2}$ & $B$ & SE B & $\beta$ \\
\hline Step 1 & $0.580^{*}$ & & & \\
$\quad$ (Constant) & & 1.177 & 0.260 & \\
$\quad$ Interest & & 0.701 & 0.042 & $0.758^{*}$ \\
$\quad$ Self-efficacy & & -0.051 & 0.051 & -0.046 \\
Step 2 & $0.635^{*}$ & & & \\
$\quad$ (Constant) & & 0.284 & 0.292 & \\
$\quad$ Interest & & 0.591 & 0.044 & $0.639^{*}$ \\
Self-efficacy & & -0.031 & 0.048 & -0.028 \\
Self-regulation & & 0.346 & 0.063 & $0.264^{*}$ \\
\end{tabular}

$* p<0.001$.

$\beta$, standardised coefficient; B, unstandardised coefficient; SE B, standard error.

In summary, among the motivational and learning variables, interest was only a significant predictor of emotional engagement; self-regulation was a significant predictor of all types of engagement and computer self-efficacy was not a significant predictor of all types of engagement.

\section{Discussion}

Factors influencing behavioural engagement, emotional engagement and cognitive engagement

Study results indicated that interest and self-regulation were positively correlated with all types of engagement, while self-efficacy was not correlated with any type of engagement. Specifically, emotional engagement was most strongly correlated with interest $(r=0.760, p<0.01)$, suggesting that it is important to facilitate emotional engagement by increasing student interest. Most of the students in this study took courses with a webcast feature (video-recorded lectures) and they agreed that multimedia helped them learn more. Previous research has also indicated that multimedia increases students' situational interest (Chen et al, 1999), number of interactions, participation and motivation (Guzley, Avanzino \& Bor, 2001). Multimedia appears to be an important tool for educators who want to increase student emotional engagement in online learning environments. 
Table 6: Hierarchical regression analysis predicting cognitive engagement from motivational variables (interest and self-efficacy) and learning variable (self-regulation)

\begin{tabular}{lcccc}
\hline Step and variable & $R^{2}$ & $B$ & SE B & $\beta$ \\
\hline Step 1 & $0.122^{*}$ & & & \\
$\quad$ (Constant) & & 2.617 & 0.370 & \\
$\quad$ Interest & & 0.316 & 0.060 & $0.347^{*}$ \\
$\quad$ Self-Efficacy & & -0.032 & 0.073 & -0.029 \\
Step 2 & $0.356^{*}$ & & & \\
$\quad$ (Constant) & & 0.809 & 0.383 & \\
$\quad$ Interest & & 0.093 & 0.058 & 0.102 \\
$\quad$ Self-efficacy & & 0.009 & 0.063 & 0.008 \\
$\quad$ Self-regulation & & 0.701 & 0.083 & $0.544^{*}$ \\
\hline
\end{tabular}

$* p<0.001$.

$\beta$, standardised coefficient; B, unstandardised coefficient; SE B, standard error.

The current study indicated that FT was significantly correlated with emotional engagement, suggesting that first-time distance education takers may have had higher anxiety level and were therefore less engaged emotionally in the online environment. In addition to the negative effect on reduced emotional engagement, previous research has shown that anxiety is negatively correlated with computer self-efficacy (Wilfong, 2006; Zhang \& Espinoza, 1998). The results of previous research are in line with Bandura's $(1986,1988,2001)$ social cognitive theory, which argued that higher anxiety produced lower self-efficacy and vice versa. The mechanism may be that students with higher computer anxiety feel less comfortable in using computer technologies and therefore demonstrated relatively lower levels of computer self-efficacy. To reduce the negative effects that may be encountered by first-time distance education takers, such as low emotional engagement and computer self-efficacy, educators should identify those who have never taken a distance education course previously and provide necessary support through a help desk or extra training to ease their anxieties.

\section{Situational interest and engagement}

The variable FT was used as an indicator of novelty in this study. Contrary to results of previous research (Chen et al, 1999; Flowerday et al, 2004), the current study found that novelty was not correlated with interest; however, it was negatively correlated with emotional engagement. In other words, the students experiencing the novelty of distance education (first-time users) had lower emotional engagement. Two factors in this study might explain how this result differed from those of previous studies. First, the context of this study (distance education) was different than the educational contexts of previous research. Second, FT was the only variable used to determine the participants' levels of novelty, which may be a weak measurement of the construct. It is also possible that other factors such as cognitive overload (Kirschner, Sweller \& Clark, 2006; Sweller, 1988, 1999), which results from the built-in limitations of working memory capacity of the human cognitive system, may be a result contending with anxiety and other extraneous factors unrelated to learning.

Consistent with previous findings (Chen et al, 1999; Flowerday et al, 2004), interest was shown to be a significant predictor of emotional engagement in hierarchical regression analyses. At the correlational level, there was a positive correlational relationship between interest and all types of engagement (behavioural engagement, emotional engagement and cognitive engagement), supporting the hypothesis that the students who were more interested in distance learning were 
more engaged in that environment. The correlation coefficient between interest and emotional engagement was higher than the correlation coefficient between interest and each of the other two types of engagement (behavioural engagement and cognitive engagement), supporting Fredricks et al's $(2004,2005)$ results that interest is one of the key factors in emotional engagement. Both behavioural engagement and cognitive engagement include 'effort' in their definition: The effort associated with behavioural engagement involves behavioural effort such as physically performing a task, and the effort in cognitive engagement emphasises effort to use cognitive learning strategies to master the learning process (Fredricks et al, 2004, 2005). This implies that educators should keep in mind that adding features such as multimedia to an online program to increase student interest may not lead to increased behavioural engagement or cognitive engagement.

\section{Computer self-efficacy and engagement}

In this study, students in the School of Engineering had higher computer self-efficacy than those in the School of Gerontology. Considering that engineering students may have had more prior experience using computer technology, this result was consistent with the results of previous studies (Compeau \& Higgins, 1995; Kinzie et al, 1994; Stone \& Henry, 2003).

Contrary to results of previous research (Bates \& Khasawneh, 2007), however, the current study indicated that computer self-efficacy was not a significant predictor of the engagement variables of behavioural engagement, emotional engagement and cognitive engagement. At the correlational level, computer self-efficacy was not found to be significantly correlated with engagement variables either. When considering this result, it is important to examine the role of self-efficacy in previous research (Bandura, 1986; Bates \& Khasawneh, 2007; DeTure, 2004; Stone \& Henry, 2003). It is possible that self-efficacy may have mediated the relationship between antecedent variables and outcome expectancy in the previous studies. In the current study, however, it was hypothesised that computer self-efficacy had a direct relationship with engagement. Results showed that without considering other factors, such as instructor support and acquired skills, computer self-efficacy had no direct effect on student engagement. This suggests that antecedent variables may be important factors in increasing distance education student engagement.

\section{Self-regulation and engagement}

Although the current study did not use a control group to compare the effects of student self-regulation in a distance education environment with those in a traditional classroom, the study did indicate that self-regulation was significantly correlated with all types of engagement included in the study (behavioural engagement, emotional engagement and cognitive engagement). Specifically, students with higher levels of self-regulation demonstrated higher levels of engagement.

Previous research has indicated that certain online activities and tools, such as discussion boards, online debates and brainstorming, can potentially facilitate online student self-regulation in the learning process (Kanuka, 2005; Seaman \& Fellenz, 1993). This study suggests the role of selfregulation as a significant predictor of engagement, implying that it is important to include such online activities in order to facilitate student engagement. This agrees with Bandura's (1986, 1988,2001 ) social cognitive theory, which views human learning as triadic reciprocal interactions among three factors: personal factors, behavioural factors and environmental factors. In a distance education environment, personal factors such as self-efficacy, self-regulation and interest are influenced by persons, their behaviour and their environment through reciprocal interactions. Therefore, online activities not only provide an opportunity for interaction in online environments but may increase student motivation and engagement. 


\section{Conclusion}

In summary, the study suggests that it is important to facilitate emotional engagement by increasing student interest, that first-time distance education takers may have had higher anxiety levels and therefore were less engaged emotionally in the online environment, that students experiencing the novelty of distance education (first time users) had lower emotional engagement, that students who were more interested in distance learning were more engaged in that environment, that computer self-efficacy was not a significant predictor of the engagement variables, and that students with higher levels of self-regulation demonstrated higher levels of engagement. Based on these findings, and consistent with other work (Chen et al, 1999; Guzley et al, 2001; Kanuka, 2005; Seaman \& Fellenz, 1993), it was concluded that the use of online activities and tools such as multimedia and discussion boards may be important ways to increase student engagement in an online learning environment. Adding these types of features to the online program increases student interest and emotional engagement but does not necessarily increase behavioural or cognitive engagement to a significant degree. Educators should identify students who are taking online courses for the first time and provide necessary technical help in order to ease their anxieties and increase their emotional encouragement levels. Finally, it is important for educators to pay attention to young students' needs for strategies that will increase their ability to selfregulate their learning in distance education environments.

\section{Limitations of the study}

An important limitation of the study is a possible selection bias. Participation was voluntary so the students who chose to participate ( $14.5 \%$ of the total survey invitation recipients) might have had higher levels of motivation than other students. If so, the study would not register the effects of low motivation. It is possible that these students may have experienced even higher levels of anxiety or lower self-efficacy, although the reasons for their non-participation remain unknown. Future studies can seek to minimise this by recruiting participants on a random basis. In addition, the study included only university-level distance education students so results should only be generalised to demographically similar students in similar environments.

\section{Recommendations for future research}

The current study looked at motivational and learning variables of situational interest, computer self-efficacy and self-regulation, engagement variables of behavioural engagement, emotional engagement and cognitive engagement and demographic control variables (eg, age and school enrolled in). Future studies can address other variables involved with student engagement. For example, Webster and Hackley's (1997) research investigated the relationship between quality of technology and student engagement in a distance learning environment. In addition, recent work has suggested that academic emotions may mediate the relationship between motivational variables and engagement, and thus may be important to assess (Pekrun, 2006; Pekrun, Elliot \& Maier, 2009). Factors such as cognitive load (Kirschner et al, 2006; Sweller, 1988, 1999) may be important factors as well, especially for novice participants.

Also, the results of this study indicated that engineering students had higher levels of computer self-efficacy and less variance in their responses [ mean $(\mathrm{M})=4.05, \mathrm{SD}=0.56]$ as compared with gerontology students $(\mathrm{M}=3.45, \mathrm{SD}=0.83)$. It may be that engineering students had more experience using computer technology, thus having higher computer self-efficacy. Future studies could recruit participants from more sources to form a more diverse sample in which participants have different levels of self-efficacy to see whether the efficacy variable has any significant effects on a heterogeneous sample.

Lastly, the participants in the current study included only students in distance education program. It would be useful for future studies to add a control group of traditional classroom 
students to compare the effects of motivational and learning factors in a distance education environment with those in a traditional classroom.

\section{Acknowledgements}

The authors would like to thank Harold O’Neil, John Walsh, Dennis Hocevar, Aaron Hagedorn, Yu-Chieh Lo, I-Shen Lai, Kun-Chih Chen, Sharon Myers, Helena Seli, Susan Metros and Edward O'Neill for sharing their expertise and advice, and Maria Henke, Jim Alejandre, Binh Tran and Neil Teixeira for distributing the study survey to distance learning students.

\section{References}

Bandura, A. (1986). Social foundations of thought and action: a social cognitive theory. Englewood Cliffs, NJ: Prentice-Hall.

Bandura, A. (1988). Organizational applications of social cognitive theory. Australian Journal of Management, 13, 2, 275-302.

Bandura, A. (1997). Self-efficacy: the exercise of control. New York: Freeman.

Bandura, A. (2001). Social cognitive theory: an agentic perspective. Annual Review of Psychology, 52, 1, $1-26$.

Bates, R. \& Khasawneh, S. (2007). Self-efficacy and college students' perceptions and use of online learning systems. Computers in Human Behavior, 23, 1, 175-191.

Chen, A., Darst, P. W. \& Pangrazi, R. P. (1999). What constitutes situational interest? Validating a construct in physical education. Measurement in Physical Education and Exercise Science, 3, 3, $157-$ 180.

Compeau, D. R. \& Higgins, C. A. (1995). Computer self-efficacy: development of a measure and initial test. MIS Quarterly, 19, 2, 189-211.

Dembo, M. H., Junge, L. G. \& Lynch, R. (2006). Becoming a self-regulated learner: implications for web-based education. In H. O' Neil (Ed.), Web-based learning: theory, research, and practice (pp. 185-202). Mahwah, NJ: Lawrence Erlbaum Associates.

DeTure, M. (2004). Cognitive style and self-efficacy: predicting student success in online distance education. American Journal of Distance Education, 18, 1, 21-38.

Eachus, P. \& Cassidy, S. (2006). Development of the Web Users Self-Efficacy Scale (WUSE). In E. Cohen (Ed.), The information universe: issues in informing science and information technology (pp. 199-210). Santa Rosa, CA: Informing Science.

Flowerday, T., Schraw, G. \& Stevens, J. (2004). The role of choice and interest in reader engagement. Journal of Experimental Education, 72, 2, 93-114.

Fredricks, J. A., Blumenfeld, P., Friedel, J. \& Paris, A. (2005). School engagement. In K. A. Moore \& L. Lippman (Eds), What do children need to flourish? Conceptualizing and measuring indicators of positive development (pp. 305-321). New York: Springer.

Fredricks, J. A., Blumenfeld, P. C. \& Paris, A. H. (2004). School engagement: potential of the concept, state of the evidence. Review of Educational Research, 74, 1, 59-109.

Guzley, R. M., Avanzino, S. \& Bor, A. (2001). Simulated computer-mediated/video-interactive distance learning: a test of motivation, interaction satisfaction, delivery, learning \& perceived effectiveness. [Online document]. Journal of Computer-Mediated Communication, 6, 3, Retrieved November 15, 2007, from http:// jcmc.indiana.edu/vol6/issue3/guzley.html

Hidi, S. (1990). Interest and its contribution as a mental resource for learning. Review of Educational Research, 60, 4, 549-571.

Hidi, S. (2006). Interest: a unique motivational variable. Educational Research Review, 1, 2, 69-82.

Hu, S. \& Kuh, G. D. (2002). Being (dis)engaged in educationally purposeful activities: the influences of student and institutional characteristics. Research in Higher Education, 43, 5, 555-575.

Kanuka, H. (2005). An exploration into facilitating higher levels of learning in a text-based Internet learning environment using diverse instructional strategies. [Online document]. Journal of Computer-Mediated Communication, 10, 3, Retrieved October 15, 2009, from http://jcmc.indiana.edu/vol10/issue3/

Kinzie, M. B., Delcourt, M. A. B. \& Powers, S. M. (1994). Computer technologies: attitudes and self-efficacy across undergraduate disciplines. Research in Higher Education, 35, 6, 745-768.

Kirschner, P. A., Sweller, J. \& Clark, R. E. (2006). Why minimal guidance during instruction does not work: an analysis of the failure of constructivist, discovery, problem-based, experiential, and inquiry-based teaching. Educational Psychologist, 41, 2, 75-86. 
Linnenbrink, E. A. \& Pintrich, P. R. (2004). Role of affect in cognitive processing in academic contexts. In D. Y. Dai \& R. J. Sternberg (Eds), Motivation, emotion, and cognition integrative perspectives on intellectual functioning and development (pp. 55-87). Mahwah, NJ: Erlbaum.

Pekrun, R. (2006). The control-value theory of achievement emotions: Assumptions, corollaries, and implications for educational research and practice. Educational Psychology Review, 18, 4, 315-341.

Pekrun, R., Elliot, A. J. \& Maier, M. A. (2009). Achievement goals and achievement emotions: Testing a model of their joint relations with academic performance. Journal of Educational Psychology, 101, 1, $115-135$.

Pintrich, P. R. \& De Groot, E. V. (1990). Motivational and self-regulated learning components of classroom academic performance. Journal of Educational Psychology, 82, 1, 33-40.

Pintrich, P. R., Smith, D. A. F., Garcia, T. \& McKeachie, W. J. (1991). A manual for the use of the Motivated Strategies for Learning Questionnaire (MSLQ). Ann Arbor, MI: The University of Michigan.

Pintrich, P. R., Schunk, D. H. \& Meece, J. L. (2008). Motivation in education: theory, research, and applications (3rd ed.). Upper Saddle River, NJ: Merrill.

Richardson, J. C. \& Newby, T. (2006). The role of students' cognitive engagement in online learning. American Journal of Distance Education, 20, 1, 23-37.

Richardson, J. T. E. \& Long, G. L. (2003). Academic engagement and perceptions of quality in distance education. Open Learning, 18, 3, 223-244.

Richardson, J. T. E., Long, G. L. \& Foster, S. B. (2004). Academic engagement in students with a hearing loss in distance education. Journal of Deaf Studies and Deaf Education, 9, 1, 68-85.

Schraw, G. \& Lehman, S. (2001). Situational interest: a review of the literature and directions for future research. Educational Psychology Review, 13, 1, 23-52.

Seaman, D. F. \& Fellenz, R. A. (1993). Effective strategies for teaching adults (2nd ed.). New York: Merrill.

Stone, R. W. \& Henry, J. W. (2003). The roles of computer self-efficacy and outcome expectancy in influencing the computer end-user's organizational commitment. Journal of End User Computing, 15, 1, 38-53.

Studenmund, A. H. (2006). Using econometrics: a practical guide (5th ed.). Boston, MA: Addison Wesley Pearson.

Sweller, J. (1988). Cognitive load during problem solving: effects on learning. Cognitive Science, 12, 2 , $257-285$.

Sweller, J. (1999). Instructional design in technical areas. Camberwell: ACER Press.

Tuckman, B. W. (2007). The effect of motivational scaffolding on procrastinators' distance learning outcomes. Computers \& Education, 49, 2, 414-422.

Wang, S. L. \& Lin, S. S. J. (2007). The application of social cognitive theory to web-based learning through NetPorts. British Journal of Educational Technology, 38, 4, 600-612.

Webster, J. \& Hackley, P. (1997). Teaching effectiveness in technology-mediated distance learning. Academy of Management Journal, 40, 6, 1282-1309.

Whipp, J. L. \& Chiarelli, S. (2004). Self-regulation in a web-based course: a case study. Educational Technology Research and Development, 52, 4, 5-22.

Wilfong, J. D. (2006). Computer anxiety and anger: the impact of computer use, computer experience, and self-efficacy beliefs. Computers in Human Behavior, 22, 6, 1001-1011.

Wolters, C. A., Pintrich, P. R. \& Karabenick, S. A. (2005). Assessing academic self-regulated learning. In K. A. Moore \& L. Lippman (Eds), What do children need to flourish? Conceptualizing and measuring indicators of positive development (pp. 251-270). New York: Springer.

Zhang, Y. \& Espinoza, S. (1998). Relationships among computer self-efficacy, attitudes toward computers, and desirability of learning computing skills. Journal of Research on Computing in Education, 30, 4, 420436.

Zimmerman, B. J. \& Risemberg, R. (1997). Self-regulatory dimensions of academic learning and motivation. In G. D. Phye (Ed.), Handbook of academic learning: construction of knowledge (pp. 105-125). San Diego, CA: Academic Press.

Zimmerman, B. J. \& Schunk, D. H. (Eds) (2001). Self-regulated learning and academic achievement: theory, research and practice. New York: Springer-Verlag. 